\title{
Vitamin D Measurement
}

National Cancer Institute

\section{Source}

National Cancer Institute. Vitamin D Measurement. NCI Thesaurus. Code C84818.

The determination of the amount of vitamin D present in a sample. 